\title{
Alternate Strip Clearcutting in Upland Black Spruce VI. Harvesting and Renewal Costs of Stripcutting Relative to Those of Clearcutting
}

\author{
by
}

John D. Johnson ${ }^{1}$ and Jack H. Smyth ${ }^{1}$

\begin{abstract}
This report identifies, estimates and compares harvest and renewal costs of strip-cut harvesting and clear-cut harvesting on the shallow-soil upland black spruce sites of north central Ontario. The additional costs and savings attributable to the strip-cut harvesting system are analyzed for 12 renewal prescriptions and two strip lengths over leave periods of 3,5 , and 10 years. In all, 72 harvest-renewal alternatives were analyzed.
\end{abstract}

\section{Résumé}

On a étudié, calculé et comparé le coût de reboisement sur des stations élevées au sol mince peuplées d'épinettes noires dans le centre-nord de l'Ontario. Les coûts et économies additionnels liés à la coupe en bandes sont étudiés dans le cas de 12 prescriptions de reboisements et de 2 longeurs de bande sur des périodes de réserve de 3,5 , et 10 ans. Une totale de 72 combinaisons ont été analysées.

\section{Introduction}

Since 1973, a cooperative research project with representation from the Great Lakes Forestry Centre, Ontario Ministry of Natural Resources (OMNR), and Domtar Inc. has been under way to explore the effectiveness of alternate stripcutting in shallow-soil upland sites as a means of obtaining natural regeneration of black spruce (Picea mariana [Mill.] B.S.P.).

The most widely employed method of harvesting in Ontario is clearcutting. Upland black spruce sites are extremely difficult to regenerate because of a limited depth of mineral soil, exposure of these sites to wind and high temperatures, extremely dry surface conditions, susceptibility of these sites to erosion, and an inadequate supply of viable seed for natural regeneration. In stripcutting, the residual strip provides seed for the regeneration of the first-cut strip; the residual strip is either seeded or planted artificially. These residual strips also protect the natural regeneration from excessive drying.

Several reports (Ketcheson 1977, 1979; Ketcheson and Smyth 1977,1978) dealing with specific economic aspects of the stripcutting project have been published to date. Details of the establishment, location, and objectives of this long-term cooperative project are well documented by Jeglum (1980).

Government of Canada, Canadian Forestry Service, Great Lakes Forestry Centre. P.O. Box 490, Sault Ste. Marie, Ontario P6A 5M7

\section{Objectives}

The objectives of the current study are to identify, estimate, and compare harvesting and regeneration costs of strip-cut harvesting and clear-cut harvesting in the shallowsoil upland black spruce sites of north central Ontario. The study does not consider costs or revenues beyond the point of stand establishment. The least-cost strategy is, therefore, not necessarily the most economically efficient strategy.

The analysis estimates the additional harvesting costs and renewal savings with alternate stripcutting for strips $183 \mathrm{~m}$ and $366 \mathrm{~m}$ in length over leave periods of 3,5 and 10 years. The analysis uses a strip width of $60 \mathrm{~m}$.

\section{Additional Harvesting Costs Attributable to Stripcutting}

Alternate stripcutting results in higher harvesting costs than conventional clearcutting. Ketcheson (1979) analyzed the additional costs of stripcutting in comparison with clearcutting on the basis of data collected from the woodlands divisions of two major companies operating on shallow-soil upland sites in northern Ontario. Relevant cost data from Ketcheson (ibid.), with some modifications, have been used in this report. All costs are in constant 1985 dollars. A real discount of $4.5 \%$ has been used. This appears to be an appropriate discount rate for long-term forestry investments as discussed by Row et al. (1981).

The following activities were identified as potential sources of harvesting costs over and above those associated with clearcutting: 
1) planning, layout and supervision

2) in-strip effects

3) roadside processing

4) movement of equipment

5) road construction and maintenance

6) losses to blowdown

Figure 1 illustrates, by leave period, additional cost elements attributable to stripcutting for the 183-m strip. Costs for the 366-m strips are similar to costs for the 183-m strips, although harvesting costs are slightly lower for the longer strips because there is a lower tertiary road density, and there is less loss to blowdown.

\section{Planning, Layout and Supervision}

The highest planning, layout and supervision costs as estimated by Ketcheson (1979) for companies operating in this site type were used. These estimates were augmented to account for the additional resources required by the operator to retype OMNR's Forest Resource Inventory (FRI) maps to a level of operational resolution appropriate for effective strip layout. A cost of $\$ 42.50 /$ ha was used to estimate additional planning, layout, and supervision costs.

\section{In-strip Effects}

The most critical assumption underlying the analysis is that felling and forwarding costs do not increase over those associated with clearcutting in the 60-m-wide strips with either the $183-m$ or the $366-m$ strip lengths. It is assumed that strip-cut operations will employ equipment configurations consistent with the strip-cutting system and appropriate to the specific site. In addition, it is assumed that blowdown in the residual strip does not significantly interfere with the productivity of equipment.

\section{Roadside Processing}

Ketcheson (1979) found that stripcutting, in comparison with clearcutting, did not increase loading and hauling costs, and that slashing costs were increased only marginally. Slashing costs were increased because two sweeps of the road were required (one for each leave period) and more time was required to move between piles. The highest additional cost of roadside processing in the two operations examined by Ketcheson (ibid.) was used in the analysis. A figure of $\$ 9.01 / \mathrm{ha}$ was used to cover additional roadside processing costs.
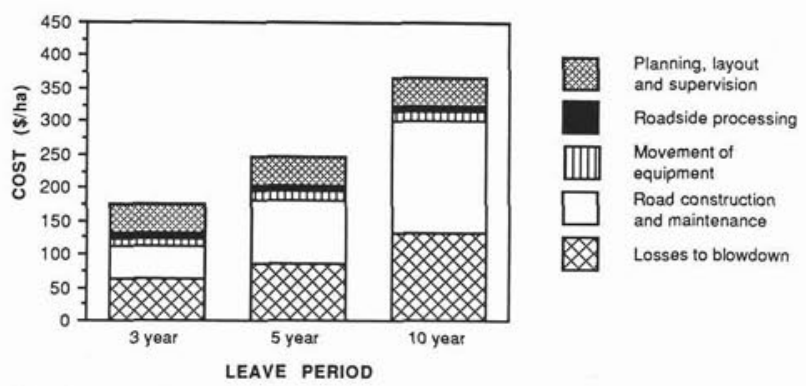

Note: The assumption is that there are no in-strip operating costs.

Figure 1. Alternative stripcutting relative to clearcutting: incremental harvesting costs, by leave period, for areas harvested in 183-m strips.

\section{Movement of Equipment}

This element includes additional cost of moving harvesting equipment to and from the site and of servicing this equipment (i.e., garage costs). In this report, the additional garage cost associated with cut and skid operations as estimated by Ketcheson (1979) was used. Additional equipment overhead charges attributable to the strip-cutting harvest system were estimated at $\$ 13.31 / \mathrm{ha}$.

\section{Road Construction and Maintenance}

Ketcheson (1979) found that the most important elements of the strip-cutting system that contribute to additional harvesting costs are road construction and maintenance. Standards of secondary and tertiary access roads do not differ from those for clear-cut operations, but twice as much area as in the clear-cutting operation must be accessed initially to obtain the same volume of timber. Accordingly, the opportunity cost associated with carrying the initial road investment over a longer period must be accounted for in the analysis. The capital charges associated with road construction vary directly with leave period.

Deterioration of tertiary haul roads increases with leave period (Ketcheson 1979). Therefore, the costs of reconstructing tertiary haul roads to standards set for the harvesting of the residual strip also vary directly with leave period.

Strip dimension affects the spacing and, therefore, the length of tertiary road construction in the strip-cutting area. It is assumed that the length of secondary haul road in the clearcut area is the same as in the area harvested under the stripcutting method, and that tertiary road length is the same in the area clear cut as in the area harvested in strips with a strip length of $183 \mathrm{~m}$.

On the other hand, the 366-m strips result in a lower tertiary road density. In 1986, Domtar Inc. forestry personnel laid out a tertiary road network using both the $183-\mathrm{m}$ and the 366-m strip lengths in an area designated for stripcutting. ${ }^{2}$ The proportion of tertiary road length necessary to access the same area in the 366-m strips was applied to the capital and maintenance costs for the 183-m-strip tertiary roads (Ketcheson 1979) to estimate capital and maintenance costs for the tertiary roads in the area laid out in the longer strips. Figure 1 shows, by leave period, the additional estimated average cost per ha of secondary and tertiary road construction and maintenance for the two strip lengths.

\section{Losses to Blowdown}

There is a loss of merchantable volume caused by blowdown in the residual strip which, under a clear-cut system, could have been retrieved and utilized. This loss to blowdown in the residual strip is, therefore, a major source of indirect costs. If we assume that the net mortality attributable to the strip-cutting system is left on the site and that in-strip productivity is not affected by this debris, then the cost of blowdown in the residual strip can be estimated as the overhead cost per cubic metre "on the stump" of accessing new harvest areas. Overhead costs include administration, planning, camp and garage costs. Fixed cost data presented in Anon. (1977) were used to estimate these costs, which totalled $\$ 12.00 / \mathrm{m}^{3}$ in 1985 .

¿L. Morrow, Domtar Inc., Red Rock, Ontario 1986 (pers. comm.) 
In this study we used a relationship between net merchantable volume lost to blowdown in the residual strip on the one hand and strip length, strip width, and leave period on the other, that was generated by Fleming and Crossfield (1983). Figure 1 provides an estimate of the volume and cost of blowdown in the residual strip by strip length and leave period.

\section{Renewal Costs of Stripcutting Relative to Those of Clearcutting}

It has been shown that, under similar site conditions, the strip-cutting harvesting system results in higher unit area harvesting costs than does the clear-cutting system. However, it is reasonable to assume that, under some conditions, it may be less expensive to establish a new stand in a strip-cut area than in an area that has been clear cut. To determine whether or not this is the case, it is necessary to estimate renewal costs in the strip-cut areas and compare these with renewal costs on similar sites that have been clear cut. Such a comparison implies that the forest manager has a choice between clearcutting and stripcutting as well as a choice among renewal options for the clear-cut and residual strip. It is assumed that the first strip will be adequately stocked by natural regeneration when the residual strip is harvested.

\section{Renewal Cost Elements}

The potential for renewal cost savings for the residual strip was estimated by examination of three major renewal cost elements: site preparation, stock/seed procurement, and planting/seeding.

\section{Site Preparation}

It was assumed that both the clear-cut and the strip-cut areas could be adequately prepared with the Bräcke Badger pulled by a skidder. No relevant cost studies have been completed to indicate whether or not site preparation in the 60 - $m$ strips would cost significantly more per unit area than it would in the clearcut. Nonetheless, discussions with experienced personnel indicate that if the "land pattern method" (Anon. 1978) were used in the residual strips, no significant scarification costs would be incurred. The flexibility of the Bräcke Badger enables the manager to modify the frequency and distance between patches to accommodate the desired renewal option without affecting the forward motion or swath width of the machine. Site preparation of the residual strip will require marking and monitoring to protect regeneration on the first cut. It is assumed that these duties can be performed by the foreman already on site and, therefore, would not generate additional costs.

\section{Stock/Seed Procurement}

Stock and seed costs for jack pine (Pinus banksiana Lamb.) and black spruce delivered within a reasonable distance of the planting area were obtained from OMNR's tree nursery at Thunder Bay. Seed procurement charges were estimated at $\$ 140.87 / \mathrm{kg}$ for jack pine (@288500 seeds $/ \mathrm{kg}$ ). Container seedling procurement charges were estimated at $\$ 180.50$ / 1000 seedlings (delivered) for jack pine and $\$ 188.50 / 1000$ seedlings (delivered) for black spruce. A planting density of 2500 trees/ha, an aerial seeding density of 50000 jack pine seeds/ha, and a spot seeding rate of 25000 seeds $/$ ha $^{3}$ were used to estimate the purchase cost of seed or stock/ha. Stock and seed costs/ha were halved in the strip-cutting system since the first strip is assumed to have seeded in naturally, and only the second strip required planting or artificial seeding.

\section{Planting/Seeding}

The operational costs associated with planting and seeding were taken from the 1985 cost schedules presented in five major Forest Management Agreements ${ }^{4}$ in the area. The highest costs were used to reflect the difficult conditions common to the shallow-soil upland sites in the study area. A 1985 planting cost of $\$ 161.09 / 1000$ seedlings and an aerial seeding cost of $\$ 6.96 /$ ha were used.

\section{Renewal Options}

The following renewal options were examined for clear-cut areas:

1) container planting black spruce or jack pine

2) aerially seeding jack pine

3) spot seeding jack pine with the Bräcke Badger.

The following renewal options were examined for the residual strips:

1) container planting black spruce or jack pine

2) spot seeding jack pine with the Bräcke Badger.

It was assumed that all clear-cut and strip-cut areas could be site prepared with the Bräcke Badger in spite of the choice of stock or renewal method. All first-cut strips were assumed to be satisfactorily stocked naturally to a desirable species.

A pairing of renewal options for the clear-cut and the residual strip can be considered a strip-cut/clear-cut renewal prescription. In all, 12 renewal prescriptions were developed. Figure 2 illustrates the renewal savings or losses attributable to the strip-cutting system by renewal prescription.

\section{Net Savings Attributable to the Strip-Cutting System}

A renewal prescription, when considered with a strip-cut harvest prescription 5 and compared with a clear-cut prescription, can be considered a harvest-renewal alternative. In all, the 12 renewal prescriptions previously discussed were analyzed, the three different leave periods and two strip lengths being used in each case, for a total of 72 harvest-renewal alternatives.

An estimate of the net saving or cost associated with harvesting and renewing a site by means of the strip-cutting system in comparison with clearcutting can be attained by summing the incremental harvesting cost and the renewal saving (or loss) for each harvest-renewal alternative. Figure 3 illustrates the structure for the costing model used to estimate the net savings attributable to the strip-cutting system.

Proponents of stripcutting would hope that the reduced renewal costs associated with stripcutting would more than offset the additional harvesting costs associated with this harvesting system. Figure 4 illustrates the net savings resulting from stripcutting relative to those resulting from clearcutting, as estimated for each harvest-renewal alternative.

\footnotetext{
3L. Morrow, Domtar Inc., Red Rock, Ontario 1986 (pers. comm.)

${ }_{4}^{4}$ F Forest Management Agreement between an individual forest company and the province of Ontario, which includes a schedule of costs to be rebated to the company by the province for eligible silvicultural work successfully completed. 5i.e., a specific strip length and leave period.
} 


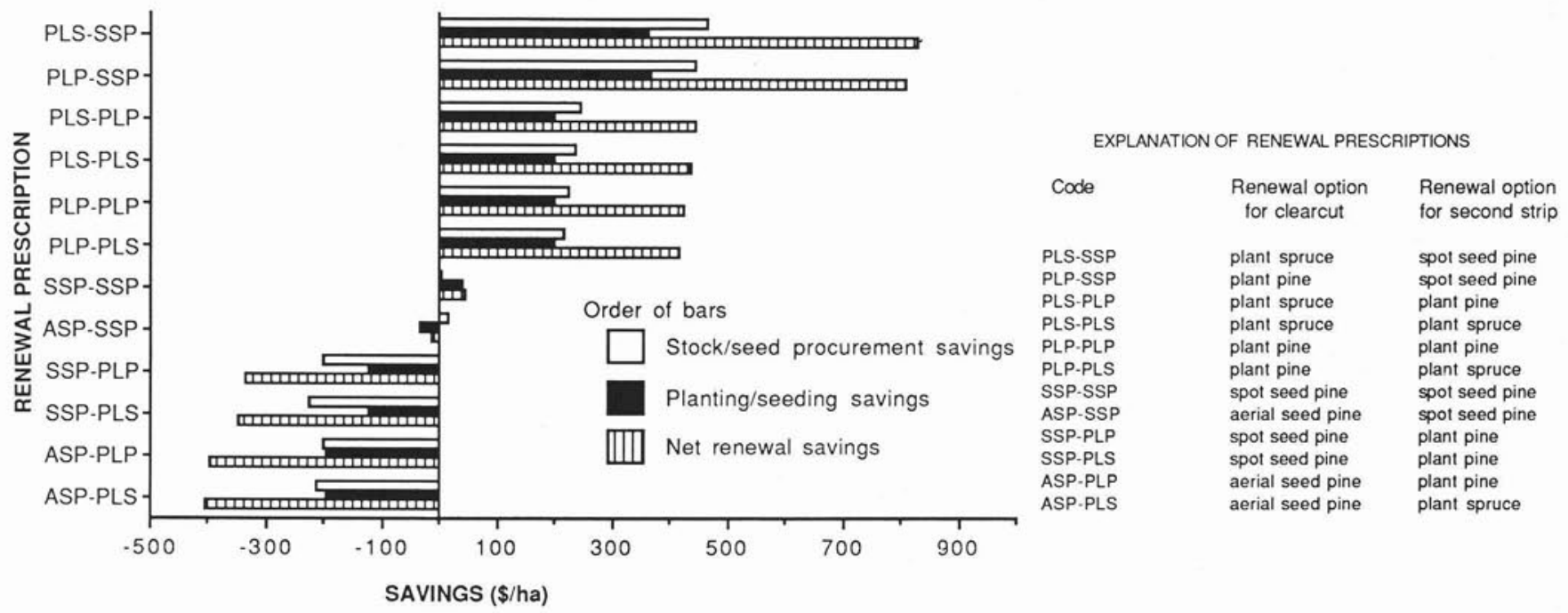

Figure 2. Alternate stripcutting relative to clearcutting: savings realized, by leave period.

Several points are worth noting in Figure 4. First, it reveals that not all of the harvest-renewal alternatives considered in this analysis result in savings. A closer examination reveals that three alternatives that compare stripcutting with clearcutting followed by seeding (aerial or spot) result in net losses. This implies that if an area can be clear cut and successfully regenerated by scarification and seeding, the manager should in all cases choose clearcutting over stripcutting regardless of which renewal option is chosen for the residual strip. This reflects the high cost of purchasing and planting container seedlings in comparison with the purchase and application of seed.

For the same reason, the alternatives that compare stripcutting with clearcutting followed by planting containerized seedlings result in net savings. This suggests that if the manager is faced with the choice of clearcutting and planting or stripcutting, he should choose stripcutting regardless of which renewal option is chosen for the residual strip.

Second, since the incremental cost of renewal of the stripcut is not dependent upon leave period or strip length, the impact of leave period and strip length on net savings or losses is the same in absolute terms in all alternatives. Accordingly, strip length and leave period have the highest relative impact on those strip-cut alternatives that result in the lowest savings or losses. These are the harvest-renewal alternatives in which the renewal option of the clearcut and the residual strip are similar. In no alternative does a change in leave period or strip length determine whether or not stripcutting is preferable to clearcutting.

Third, longer strips result in marginally higher net savings for each harvest-renewal alternative examined. This is explained by the lower tertiary road density required in the longer strips and by the lower losses to blowdown in the longer strips. Also, doubling the strip length does not result in significantly large savings for a given harvest-renewal alternative. The relative impact of strip length is greatest over the longest leave periods.

Finally, reductions in the leave period result in higher savings. This is explained by the compounding effect associated with road construction capital costs, lower road reconstruction charges for shorter leave periods, and the direct relationship between leave period and blowdown established in Fleming and Crossfield (1983).

Shorter leave periods are desirable because they are less costly; however, the choice of leave period ultimately depends on the ability of the first strip to regenerate naturally to achieve adequate stocking. Leave periods can be reduced by improving the receptivity of the seedbed. Managers, however, should be aware of tradeoffs between reductions in the leave period and higher site preparation costs in the initial strip.

\section{Discussion}

Treatment costs and stand values have not been estimated beyond the point of stand establishment. The harvestrenewal alternative with the greatest savings, therefore, might not be the alternative with the highest economic value. The least-cost (highest savings) harvest-renewal alternative will have the highest value only if all stands resulting from these alternatives are assumed to have the same net present value. Realistically, the established stands resulting from the different renewal options used in this analysis will vary considerably depending on species mix, tending requirements, and rotation age.

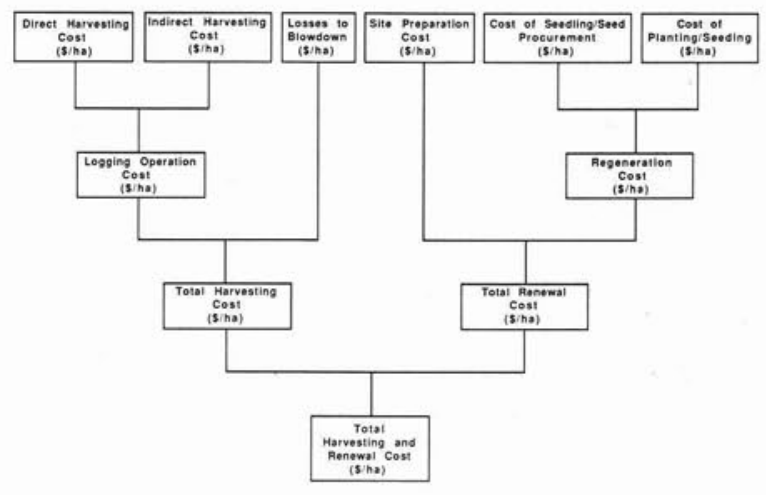

Figure 3. Economic model developed to estimate net savings attributable to the strip-cut harvesting system. 


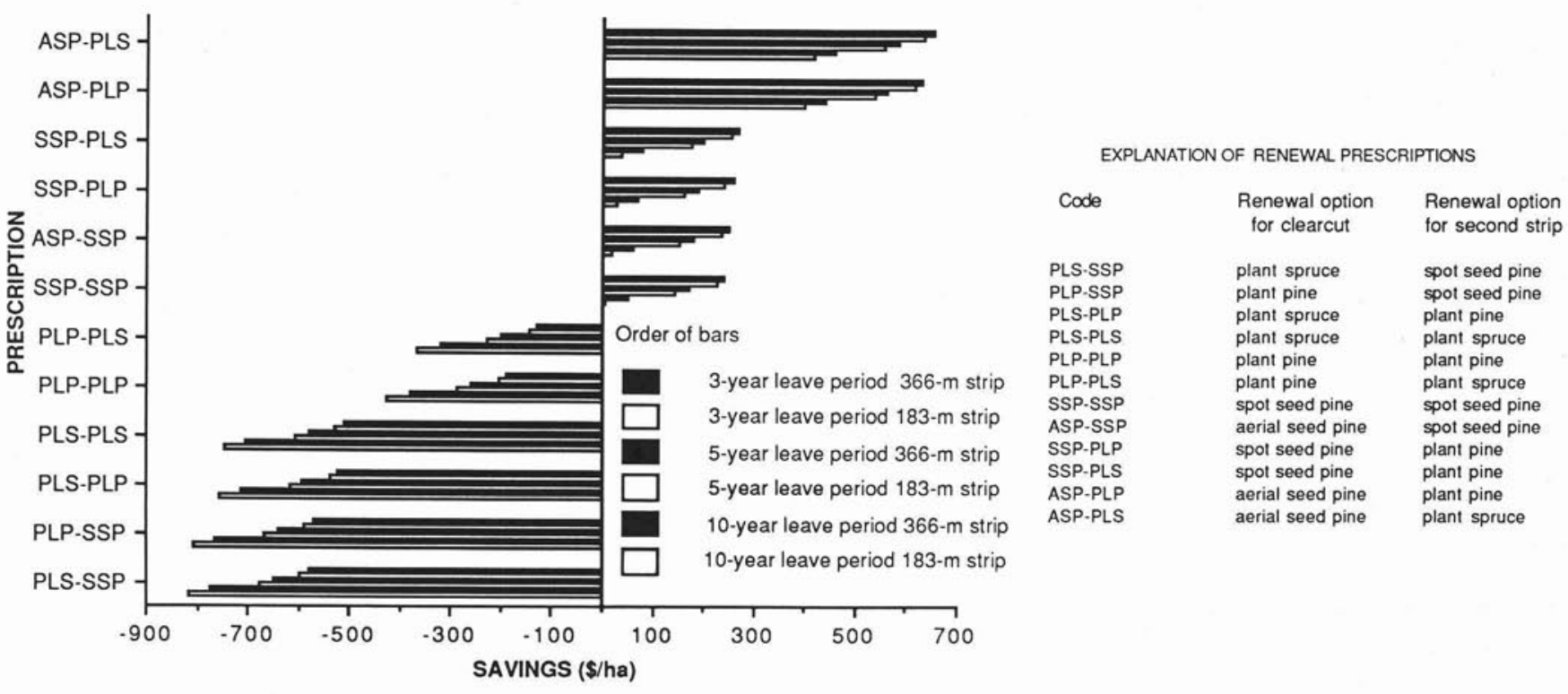

Figure 4. Alternate stripcutting relative to clearcutting: net harvesting and renewal savings, by leave period, strip length, and renewal prescription.

An assumption underlying the analysis is that stripcutting will not result in any reduction in extraction productivity. An increase in extraction costs of only $\$ 6 / \mathrm{m}^{3}$ would negate the savings of even the best strip-cutting and renewal options examined in the analysis. Managers who believe that extraction productivity will suffer during stripcutting would be wise not to employ this harvesting method.

The decision to strip cut or not cannot be based solely on cost. Often the choice of harvest and renewal systems will be determined by the site itself. In some cases, the choice might be to strip cut an area or designate it a protection forest. In other cases, sites might be operable with a strip-cut system, but the relatively high cost of such a system cannot be justified.

Clearly, forest managers in Canada will be interested in generating renewal savings only if these savings can be applied against the higher harvesting costs associated with stripcutting. In some cases, however, the organization that has direct financial responsibility for harvesting is not the same one that is financially responsible for renewal costs. In these situations, the most efficient combination of harvesting and renewal operations may not be chosen. Because strip-cutting always results in higher harvesting costs, it is understandable that operations managers who do not realize the renewal savings will discriminate against this harvesting system. It is unlikely that strip-cutting will gain wide acceptance until these institutional constraints are removed.

\section{Conclusions}

1) Stripcutting increases harvesting costs.

2) Stripcutting is less costly than clearcutting followed by planting but more costly than clearcutting followed by seeding.

3) Increasing the leave period results in higher harvesting costs; leave periods of up to 10 years are acceptable, but not desirable.

4) Doubling strip length from 183 to $366 \mathrm{~m}$ does not significantly affect harvesting costs.

\section{Recommendations}

1) Managers should consider stripcutting a more cost-effective means of harvesting than clearcutting for those harvest- renewal alternatives in which renewal savings more than offset the additional harvesting costs.

2) Managers should make every effort to minimize leave periods.

3) Since increasing strip length does not significantly reduce harvesting costs, operations personnel should use a flexible strip length to accommodate site-specific operating constraints such as topography, tertiary road construction cost, and configuration of extraction equipment.

4) When the organization that is financially responsible for renewal costs is not the same one that is responsible for harvesting costs, arrangements should be made to ensure that the most cost-efficient harvest/renewal system is employed.

\section{References}

Anon. 1977. Analysis of wood costs in the North American forest products industry. Dep. Ind. Trade and Comm., Resour. Ind. Br. For. Prod. Group, Ottawa, Ont. $46 \mathrm{p}$.

Anon. 1978. Scarification. Forskningsstiftelsen Skogsarbeten, Stockholm, Sweden. 32 p.

Fleming, R.L. and R.M. Crossfield. 1983. Strip cutting in shallowsoil upland black spruce near Nipigon, Ontario. III. Windfall and mortality in the leave strips: preliminary results. Dep. Environ. Can. For. Serv., Sault Ste. Marie, Ont. Inf. Rep. O-X-354. 27 p.

Jeglum, J.K. 1980. Stripcutting in shallow-soil upland black spruce near Nipigon, Ontario. I. Study establishment and site conditions. Dep. Environ., Can. For. Serv., Sault Ste. Marie, Ont. Report O-X-315.60 p. + appendices.

Ketcheson, D.E. 1977. The impact of strip cutting on logging road costs. Dep. Fish. Environ., Can. For. Serv., Sault Ste. Marie, Ont. Report O-X-263.19 p

Ketcheson, D.E. 1979. A study of the cost of strip cutting black spruce stands in northern Ontario. Dep. Environ., Can. For. Serv., Sault Ste. Marie, Ont. Report O-X-301.23 p.

Ketcheson, D.E. and J.H. Smyth. 1977. The impact of stripcutting on slashing costs. Dep. Environ. Can. For. Serv. Sault Ste. Marie, Ont. Unpubl. rep.

Ketcheson, D.E. and J.H. Smyth. 1978. Impact of strip cutting on logging costs. Dep. Environ., Can. For. Serv. Sault Ste. Marie, Ont. For. Res. Newsl., Summer 1978.

Row, C.H., F. Kaiser and J. Sessions. 1981. Discount rate for longterm forest service investments. J. For. 79: 367. 